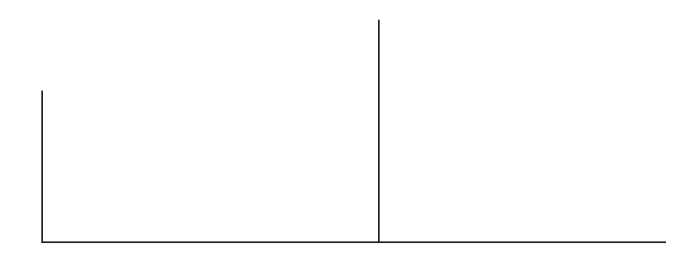

\title{
As províncias da angústia (Roteiro de viagem)
}

\author{
Luís Claudio Figueiredo
}

O presente trabalho tem como propósito sugerir que, embora as teorizações freudianas relativas à angústia tragam as marcas da Matriz Funcionalista provenientes da funda inserção do autor no campo da biologia evolucionista do século XIX, aqui como em outras partes, a pesquisa psicanalítica leva Freud a romper com alguns dos pressupostos do funcionalismo. Basicamente, as ênfases na adaptação, na auto-equilibração $e$ na temporalidade concebida em termos de evolução $e$ desenvolvimento devem ceder terreno diante de uma consideração mais detida da angústia na experiência humana. É a partir daí que uma interlocução com os filósofos Heidegger e Lévinas pode ser procurada como meio de facilitar a emergência no próprio corpo teórico e clínico da Psicanálise de algumas perspectivas já entrevistas por Freud e que não poderiam ser plenamente acolhidas enquanto o pensamento psicanalítico permanecesse sob o domínio do funcionalismo. 


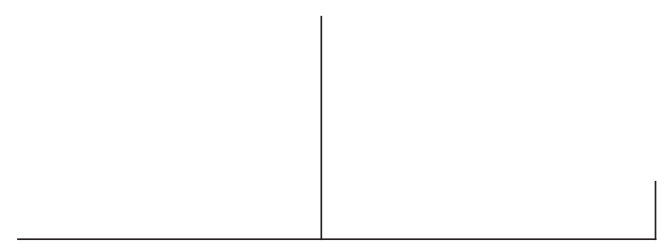

\section{Considerações preliminares}

O nascimento da Biologia científica no século XIX se deu através de diferentes vias: a biologia evolucionista, a paleontologia, a embriologia, a anatomia comparada e a fisiologia dos mecanismos auto-regulados desenvolveram-se guardando uma certa independência e, eventualmente, até entrando em choque uma com outras. Por exemplo, alguns paleontólogos da época repudiavam o evolucionismo. Contudo, todas estas vertentes dos estudos biológicos encarnavam e traziam subsídios para a consolidação do que pode ser denominado de Matriz Funcionalista e Organicista (Figueiredo, 1997). Esta Matriz, que teve influência determinante na estruturação dos estudos psicológicos, organiza-se em torno de alguns conceitos-chave. Refiro-me aos conceitos de adaptação, função, organismos - entendidos como estruturas funcionais hierarquizadas -, equilíbrio e processos de auto-equilibração e, finalmente, evolução e desenvolvimento. Freud, em sua formação no campo da medicina e da biologia, parece ter sido profundamente marcado por estas noções, ainda que conceitos de outras proveniências também tenham sido importantes para ele, como, por exemplo, os de extração romântica e vitalista. Trata-se, neste texto, de ver como e porque a Matriz Funcionalista está presente, mas precisa ser confrontada e "superada" para que a psicanálise possa lidar com o "não-funcional" no funcionamento psíquico. Porém, as aspas em "superada" devem-se a que os pressupostos funcionalistas, mesmo não correspondendo às exigências da teorização e da clínica psicanalíticas, que nos requer e nos remete a outras possibilidades de pensamento, são indispensáveis para a articulação básica de seus conceitos. Nesta medida, a biologia funcionalista não pertence apenas ao passado epistemológico da psicanálise, nem funciona apenas como parte do horizonte externo das produções freudianas, mas integra o próprio corpo do pensamento psicanalítico, que nela lança suas raízes, ainda que venha a ser 


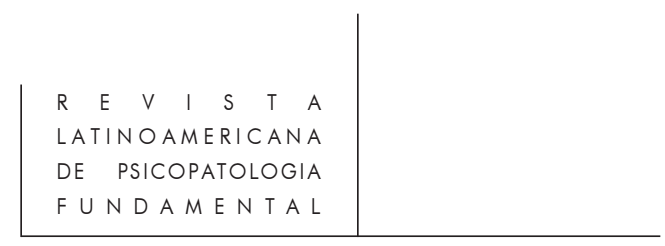

permanentemente "superada" pela própria psicanálise. Como veremos, o esquema funcionalista é a base sobre a qual as teses freudianas são expostas e, no entanto, será sobre uma lógica que transcende a lógica funcional que estas mesmas teses podem se sustentar.

\section{A Angústia no referencial funcionalista da biologia evolucionista (Freud)}

$\mathrm{Na}$ primeira teoria freudiana da angústia (elaborada desde a década de 90 e mantida ao longo dos anos) postula-se a transformação automática da libido reprimida em angústia para a manutenção de um nível mínimo e/ou ótimo de tensão. Aqui se revela um mecanismo de auto-equilibração funcionalmente concebido. Convém assim ressaltar o valor adaptativo da angústia no processo de auto-equilibração e o caráter funcional dos sintomas que atuam como um dispositivo de religação da energia livre, ou seja, da energia que permanece desligada de representações adequadas. Desta maneira, há ganhos funcionais e adaptativos, em termos de manutenção de condições ótimas de funcionamento do "ambiente interno" - o psiquismo - tanto na angústia como na formação de sintomas, em que pesem as óbvias desvantagens destes modos de auto-regulação para o indivíduo ${ }^{1}$. Contudo, esta falta de funcionalidade relativa não contradiz em nada a ótica funcional, já que, dada a diversidade das funções a serem exercidas e uma certa divergência entre as exigências adaptativas, uma adaptação perfeita é sempre impossível. O que se verifica na prática das relações do organismo com seu meio externo, e com seu meio interno, são sempre soluções de compromisso em que os ganhos superam as perdas, mas não as evitam completamente. Os estudos biológicos são perfeitamente capazes de integrar às suas teorias funcionalistas estes fenômenos complexos em que tanto se manifestam conflitos como soluções parciais e não plenamente satisfatórias de conflitos.

A segunda teoria freudiana da angústia, elaborada em "Inibição, sintoma e angústia" (1926)² é ainda mais nitidamente funcionalista. Nela, a "angústia" na sua dimensão psicofisiológica - é concebida como reação natural, adaptativa e funcional às situações traumáticas em que se dá o rompimento de alguma

1. Ver a propósito a sistematização muito clara elaborada por Roberto Menezes de Oliveira em sua dissertação de Mestrado "Angústia - emergência e soluções na clínica psicanalítica", defendida no Departamento de Psicologia Clínica da UnB (pp. 66, 75 e 77-78).

2. Estarei utilizando para todas as obras de Freud mencionadas a tradução argentina de José Etcheverry das Obras Completas publicada pela Amorrortu Editores, com exceção do Projeto para uma psicologia, lido na tradução para o português de Osmyr Gabbi Jr. e publicada pela Editora Imago. 


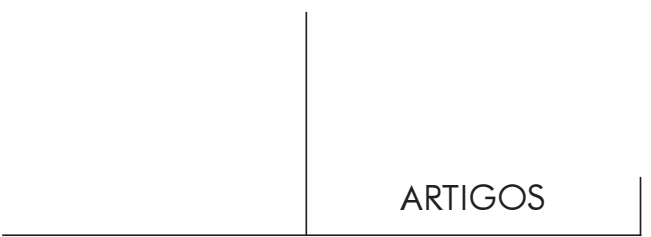

unidade ou continuidade vital, situação em que se experimenta uma vivência de passividade radical. Em seguida, a angústia, mas agora como sinal deflagrado em situações de perigo, funcionaria como um dispositivo do eu para o enfrentamento antecipado das emergências pulsionais (provenientes do Isso) mediante a produção de uma dose moderada de desprazer que mobiliza as forças do Isso para a tarefa da repressão segundo o princípio de prazer. A metáfora da vacina pode nos ser útil: uma dose moderada do agente nocivo é injetada antecipadamente para acionar as defesas do organismo e para prepará-lo para um ataque futuro. A vivência da angústia em sua forma e função de sinal "vacina" o psiquismo para que ele possa se defender de ataques que, na ausência desta preparação, seriam traumáticos. Ressalte-se, novamente, o valor adaptativo e funcional tanto das angústias como também dos sintomas. Agora, na concepção freudiana, os sintomas (inibições, fobias, compulsões) "servem" efetivamente para evitar as situações de perigo. Freud é categórico: "O valor biológico do afeto de angústia obtinha seu reconhecimento ao admitir-se que a reação de angústia era a reação geral diante de situações de perigo". (p. 151)

Até aqui parece que transitamos pela estrada bem pavimentada do pensamento funcionalista. Contudo, algumas observações vão se impondo à medida que entramos mais em contato com o texto de Freud.

\section{A estranha temporalidade das angústias}

Freud oferece, em princípio, um esquema aparentemente desenvolvimentista para "contar a história" das angústias. Há uma "origem" natural: o desamparo primordial e arquetípico do nascimento concebido como fato biológico, mas não como experiência: seria a "angústia" na sua dimensão psicofisiológica. Há, em seguida, uma sucessão de formas da angústia vivenciada - angústia de separação, de castração e de morte, esta decorrente da ameaça de abandono pelo Super-eu, abandono vivido como "poderes do destino". Estas modalidades de angústia parecem correspondentes às fases de constituição e desenvolvimento do Eu. É interessante considerar que em uma nota a "Além do princípio do prazer" (Freud, 1920/1993) Strachey (p. 13, nota 3) observa que a distinção que Freud faz, nesse trabalho de 1920, entre Terror, Medo e Angústia (Ansiedade, na tradução inglesa), distinção que em geral Freud não faz, usando estes termos mais ou menos indiscriminadamente, talvez correspondesse à diferença entre a angústia como resposta psicofisiológica - que seria na verdade Terror (Schreck) - e a Angústia como sinal, na qual se inclui uma noção de expectativa e de antecipação do perigo.

Contudo, nas considerações sobre a "origem" o argumento começa a se complicar: o "trauma" do nascimento envolve (objetivamente) um risco de morte 
e uma sobre-excitação sem anteparo [sem pára-choque], mas isso ocorre na vigência de um psiquismo rudimentar, e, mais ainda, na ausência de um $E u$ constituído e de possibilidade de registro. Trata-se, assim, no caso desta angústia natural ou terror, de uma origem apenas arquetípica e não-vivenciada. Contudo, muitas vezes Freud sente-se obrigado a falar efetivamente em uma "primeira vivência individual de angústia" (p. 89, grifo meu) associada ao nascimento.

Freud, na verdade, parece não poder abrir mão da hipótese de uma "origem" que de alguma forma faça parte da experiência do sujeito, ou seja, de uma vivência original muito precoce, mesmo que, paradoxalmente, não-vivenciada (ou não concebivelmente vivenciada), para sustentar o esquema desenvolvimentista básico. Ele dirá, por exemplo: "É fácil dizer que o recém-nascido repetirá o afeto da angústia em todas as situações que o recordem do nascimento" (p. 128, grifos meus). E ainda: "A angústia sentida no nascimento passou a ser o arquétipo de um afeto de angústia que devia compartilhar com os outros afetos o mesmo destino" (p. 151, grifo meu). Ou seja, ora é vivência - no plano ontogenético (o que não faz sentido na teoria), ora é apenas arquétipo - o que nos remete ao plano filogenético. Mas mesmo neste caso algo da sensação de angústia, da vivência angustiante, precisa ser retido para que se possa pensar nas repetições segundo um esquema funcional e desenvolvimentista. No esquema funcionalista cada nova forma manifestada ao longo do desenvolvimento é diferente da anterior, mas conserva uma mesma função básica; no caso, a de responder defensivamente ao traumatismo atual e/ou à sua aproximação. Por outro lado, não fica claro como este "episódio de origem" da angústia - em que, teoricamente, não pode ter havido nenhuma vivência de angústia e em que, principalmente, não pode ter havido angústia com a função de sinal, o que já pressupõe o $E u$ constituído - possa, ainda assim, fazer parte (como origem e protótipo) da série das vivências de angústia que se seguem. Como entender nesta situação a própria noção de origem?

Uma rápida passagem por Winnicott (1994) e pela sua teoria acerca do medo do colapso nos leva a uma situação muito similar: algo se "passou" - uma agonia inominável - quando ainda não havia sujeito capaz de experimentá-lo. O nãoexperimentado, porém, deixou seqüelas, traços, e se hoje não é possível lembrarse efetivamente deste "passado", é necessário "vivê-lo pela primeira vez - na transferência - para constituí-lo como experiência e elaborá-lo". (pp. 130-131)

Retornando a Freud, poderíamos conceber a angústia, entendida como sinal, como sendo uma resposta defensiva do $E u$ que "reproduz" em doses moderadas e toleráveis (pp. 155-156) uma vivência de uma época em que não havia sujeito constituído para "vivê-la" (e se houvesse, diga-se de passagem, sairia desta experiência dilacerado dada a radicalidade da agonia aterrorizante).

Nesta medida, a "primeira vez" da vivência de angústia, e todas as posteriores, seriam "repetições" da situação dita "arquetípica", mas só na 


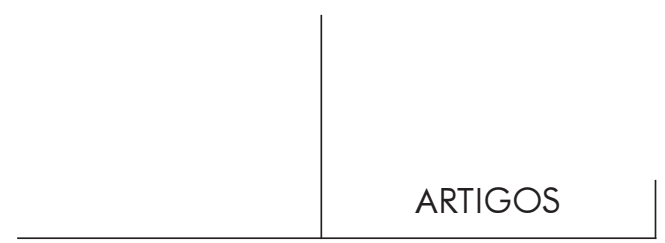

"repetição" o "passado" - o do indivíduo ou o da espécie - se constituiria como experiência, ou seja, apenas na posterioridade de um Eu constituído se constituiria a "origem arquetípica" de uma experiência que, de alguma forma não podia ter sido vivida antes, mas que, devemos necessariamente admiti-lo, havia deixado traços que funcionavam como um apelo de sentido, como um apelo ao suplemento de sentido que "só depois" se converteria em experiência vivida.

Por isso, talvez, Freud admita que, embora a situação traumática arquetípica seja a do nascimento (pp. 128 e 151), sendo desde então "recordada" nas vezes posteriores, a intensidade da vivência de angústia não é máxima no nascimento - se é que aí possa ser efetivamente vivida alguma angústia - e vá aumentando até um certo período (cf. p. 129, onde Freud, inclusive, fala novamente que "é inegável a presença de certo estado angustiado no lactante"). O mais provável é que não tenha havido angústia vivida no início, nem terror plenamente experimentado como tal, mas que, na posterioridade, ela seja de fato vivida e, eventualmente, "recordada", como "tendo sido vivida antes" e que as repetições atualizem e façam existir no "só depois" o que era mero apelo de sentido no tempo objetivo da sua "primeira ocorrência". Podemos também supor que este "mero apelo de suplemento de sentido" tem aquele caráter de agonia inominável ou terror que ocorre quando ainda não há sujeito de experiência constituído e muito menos um Eu capaz de antecipar defesas em situações de perigo. Esta interpretação, como se vê, nos levaria ao velho tema freudiano das lembranças encobridoras. Já em 1899 nos dissera Freud: "Nossas recordações da infância nos mostram os primeiros anos não como foram, mas como apareceram em tempos posteriores de despertar. Nestes tempos de despertar, as lembranças da infância não afloraram, como se costuma dizer, senão que neste momento se formaram" (Obras completas, vol. III, p. 315). ${ }^{3}$

Vale a pena considerar, neste momento, a dialética do apoio-posterioridade, sugerida por Le Guen (1991) para se pensar a temporalidade psicanalítica como uma possibilidade interessante para entender o que está aqui envolvido. No entanto, neste caso em que se trataria da passagem do arquétipo não vivenciado

3. É curioso observar que Winnicott, cujo texto sobre o "Medo ao colapso" nos sugere a possibilidade de ter existido uma "experiência" muito precoce e devastadora quando ainda não havia sujeito para vivê-la e cuja lembrança seria impossível, sendo apenas possível experimentá-la pela primeira vez na transferência, em um texto mais antigo (Winnicott, 1949) trata das lembranças do nascimento como possíveis e reais. É verdade que admite não acreditar "nos detalhes descritos como recordação" - estes seriam da ordem do encobrimento -, mas afirma que "estava preparado para acreditar no afeto que os acompanha", o que supõe, portanto, uma base mnêmica que já pertence ao plano do sentido. A posição de Freud quanto a este assunto é bem mais radical. 


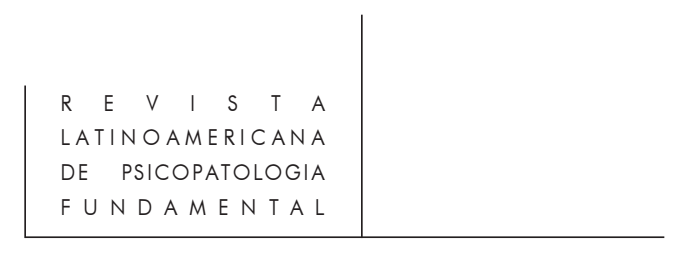

ou do puro traço mnêmico para o plano do sentido, ela não parece suficiente. Entre o evento-apoio e o evento ou condição que marca o segundo tempo do trauma deve haver uma certa identidade para que se dê uma re-significação do primeiro na posterioridade. Por exemplo: uma cena de sedução infantil, e neste momento anódina ou moderadamente prazerosa, deve guardar uma certa semelhança com o experimentado, sabido e desejado depois da puberdade para que, neste segundo tempo, adquira um novo sentido e uma eficácia traumatizante. Ou seja, há diferença, mas deve haver também identidade entre os eventos para que o efeito do "pós-golpe" (Nachträglichkeit) se verifique (cf. Lagrange, 1988, para uma detalhada análise da questão da identidade e da diferença no trauma em dois tempos postulado por Freud). Em outras palavras: o evento-apoio já deve pertencer ao campo do sentido para poder ser assemelhado ao que vem depois e dele receber um impacto seletivo. Mas qual a semelhança entre uma angústia meramente arquetípica e as angústias vividas mais tarde, e, em especial, a angústia na sua função de sinal? Fique aqui, por enquanto, apenas registrado o impasse a que retornaremos mais tarde ao final das considerações sobre a angústia no pensamento de Heidegger.

Passando adiante destas considerações acerca da "origem arquetípica" da angústia, considerações que extrapolam os limites da Matriz Funcionalista no que concerne à temporalidade dos processos psíquicos, poderemos ver também que, embora as formas da angústia "evoluam" de acordo com o "desenvolvimento" do $E u$, o $E u$ mais "evoluído" não fica livre de angústias mais primitivas nem da sobreposição e soma de angústias de diferentes naturezas (p. 134). Não se trata apenas de uma regressão, o que ainda poderia ser pensado em termos funcionais e adaptativos, mas de uma sobreposição de angústias que desarticula o esquema funcionalista à medida que a eclosão sobreposta de angústias cria situações muito pouco adaptativas. O que parece ocorrer nestas situações é, e aqui sim a dialética do apoio-posterioridade nos será útil, uma atualização e re-significação de "experiências passadas" sob o impacto de "novas experiências" que, de um ponto de vista cronológico simples, seriam apenas "repetições", mas que, do ponto de vista da temporalidade psíquica, são o segundo tempo original de um passado re-efetivado.

Além destas questões referentes à temporalidade e aos "tempos", a consideração das posições do outro nas angústias nos levará, igualmente, ao rompimento com a Matriz Funcionalista.

Em "Inibição, sintoma e angústia" a posição do "outro" é concebida como a de um protetor onipotente e benévolo a cuja ausência o bebê reage, adaptativamente, com angústia (angústia de separação).

Também na angústia de castração - em que já aparece um outro ameaçador, o pai - o que se verificaria, em última instância, seria o medo de uma separação 


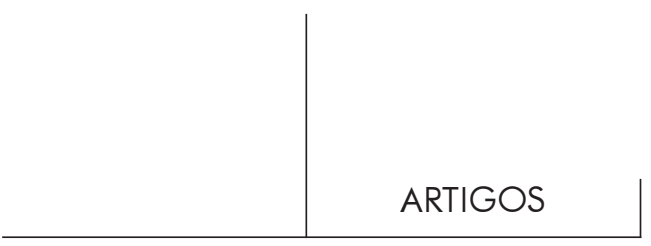

da mãe (perda da proteção benevolente), já que a perda do pênis seria a perda de uma possibilidade de reunião com ela pela via genital (p. 131). Aqui, também, a angústia é funcional já que inibe pulsões que poriam em risco a proximidade e a ligação com o agente prestativo original.

Será preciso sair deste texto e recuar muito no tempo para encontrar um panorama mais complexo e contraditório.

Há, efetivamente no "Projeto..." de 1895 (Freud, 1895/1995) uma intuição mais complexa e paradoxal, se pensássemos em termos estritamente funcionais: ali o outro é concebido simultaneamente como fonte direta de satisfação, único poder auxiliar e primeiro objeto hostil, o que rompe com o esquema adaptativo simples em que o "grito de socorro" do desamparado é endereçado em linha reta a um agente prestativo benevolente (cf. p. 44 e nota 172). Se no desamparo o grito que atrai cuidados também atrai para a proximidade "o primeiro objeto hostil", há uma disfunção associada à função, uma desadaptação mesclada à adaptação. Algo parecido poderia sem encontrado no reino animal: a cria que, faminta, chama os pais, atrai predadores e uma solução de compromisso precisa ser adotada. Os etólogos já descobriram muitos procedimentos sutis forjados pela seleção natural das espécies para enfrentar estes conflitos funcionais. A diferença crucial com o caso dos humanos é que, segundo a descrição de Freud, o mesmo objeto traz socorro, aterroriza e persegue o bebê e embora o primeiro aspecto deva predominar em condições normais de desenvolvimento, o segundo deixa suas marcas indeléveis na formação do psiquismo. Ou seja, o psiquismo se formaria trazendo para perto e alojando dentro de si o outro aterrorizante, sem o qual, porém, o bebê não poderia enfrentar seu desamparo. Haveria, portanto, necessariamente, na própria fundação do psiquismo, tanto uma sustentação pelo outro como uma introjeção do outro agressor. Assinalo que Monique Schneider (1997) retoma esta questão num texto destinado a mostrar um certo empobrecimento (de caráter defensivo) do pensamento freudiano no que concerne à posição das alteridades. Este trabalho de Monique Schneider pertence a uma coletânea em homenagem a Lévinas e a esta questão retornaremos adiante, ao final de umas breves considerações acerca do pensamento deste autor.

Enfim, são os limites da explicação funcional, vale dizer, é a controversa relação de Freud com a Matriz Funcionalista da biologia evolutiva, que nos leva a aventar a conveniência de uma interlocução da psicanálise com elaborações filosóficas não funcionalistas (Heidegger e Lévinas), não tanto para introduzi-las no pensamento freudiano como para, neste confronto, abrir para a psicanálise possibilidades de pensar mais longe o que ela já pensa. Uma pequena amostra dos ganhos desta interlocução será apresentada a seguir na forma de notas bastante resumidas e esquemáticas que mereceriam, sem dúvida, um maior desdobramento em outro trabalho. 


\section{A Angústia na analítica existencial (Heidegger, 1927/1988/89)}

Comecemos, muito esquematicamente, recordando a noção do "humano", do ser-aí como abertura [disposição afetiva, compreensão prévia e linguagem] e cura [ser-adiante-de-si]; recordemos a dimensão da facticidade [a condição de ser-lançado no já-aí, de ser lançado e abandonado em um mundo não escolhido] e a dimensão da existência [a condição de ser-para, ser-na-direçãode-suas-possibilidades, ser-fora-de-si]. Recordemos, finalmente, a condição primordial de ser-no-mundo como estrangeiro.

É na insustentabilidade desta experiência que se enraíza o que Heidegger denomina (em uma tradução repleta de ressonâncias moralizantes que nada tem a ver com o pensamento do autor) de decadência: trata-se do "lidar-com-osentes" nas ocupações e preocupações para neles se apoiar, para neles se alienar; trata-se do familiarizar-se no/do cotidiano, do entregar-se às rotinas; trata-se da intersubjetividade cotidiana como território do impessoal sob cuja tutela vive-se de início e a maior parte do tempo, dando ouvidos ao falatório, participando dele etc.

É neste contexto que se pode entender a experiência da suspensão ou interrupção angustiante do lidar cotidiano (este lidar funcional, rotineiro, tagarela e coletivo) em que se opera um certo retorno a si como abertura e ex-posição: a angústia constitui-se, assim, como o "conhecimento" mudo do nada sobre o qual nos mantemos em suspenso, sobre o qual nos pro-jetamos com tudo que isto carrega de contingência, efemeridade, precariedade, "inutilidade" etc. Mas este nada, este vazio de formas, este nada de entes em que essencialmente nos mantemos em suspenso, em que pesem os dispositivos de sustentação do cotidiano, deve ser também concebido como uma "plenitude secreta", como a possibilitação dos entes no seu vir-a-ser. E a experiência da angústia que nos corta o fôlego é a experiência deste nada e desta abertura como possibilitação de novas e infinitamente variáveis formas e entes.

Pois bem, a angústia não tem uma "causa" nem uma "função", é uma disposição afetiva original da existência embora "de início e a maior parte do tempo" estejamos protegidos dela (protegidos do ser como possibilitação, protegidos do vir-a-ser, protegidos do tempo). Ela é parte da nossa condição e pode emergir sem qualquer causa específica. $\mathrm{Na}$ verdade, muito ao contrário, ela nos arranca dos encadeamentos, ela nos devolve à contingência e ao acaso primordiais.

Nos termos de Heidegger, é indispensável proceder a algumas distinções: há, de um lado, o lado fundamental, a angústia (incausada e disruptiva de toda funcionalidade) e, de outro, o medo, o pavor, o terror, a ansiedade e, estes sim, são funcionais: a função é a de servirem como fugas da angústia na direção dos entes. 


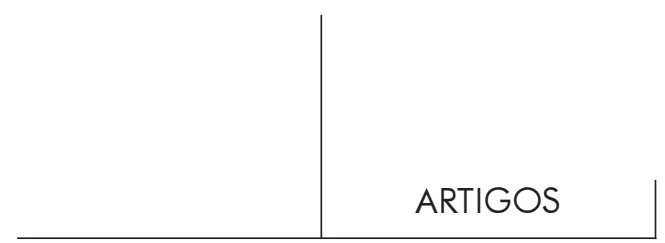

Se formos buscar um rápido confronto entre Heidegger e Freud veremos que para os dois há uma ausência de representação e de objeto determinado na angústia. Diz Freud: “[a angústia] leva aderida uma indeterminação e ausência de objeto" (p. 154). Ou, em "Além do princípio do prazer", onde Freud se propõe a fazer um uso mais discriminado dos termos: "A angústia designa certo estado como de expectativa frente ao perigo e preparação para ele, mesmo que se trate de um perigo desconhecido; o medo requer um objeto determinado" (p. 12). Para Heidegger, igualmente, a angústia é a experiência do nada, ou seja, ela carece de entes sobre os quais se apoiar, carece de objetos determinados. Em Freud, contudo, como se viu acima, ao contrário do que se pode pensar em termos heideggerianos, o sinal de angústia e (os sintomas) devem ser entendidos como dispositivos funcionais de evitação do perigo. Talvez o que Freud chame de angústia, ao se referir à angústia como sinal, pudesse ser mais bem compreendido nos termos heideggerianos como uma forma generalizada e difusa de medo - a ansiedade, em que a expectativa de um perigo difuso que se aproxima prepara o indivíduo para a sua chegada. Já para Heidegger, por pior que seja o medo em qualquer de suas formas, ele ainda assim pertence aos procedimentos por meio dos quais evitamos o pior, a experiência angustiante de nos descobrirmos suspensos sobre o abismo, sobre o fundo sem fundo.

Vamos acrescentar agora algumas novas determinações na consideração do modo de ser que nos coube: trata-se de interpretar o ser-aí como ser-lançado, sem escolha, no mundo e no tempo e como ser-para-a-morte. Nascimento e morte devem ser entendidos, em termos heideggerianos, como fatos da vida com os quais nos cabe lidar, mas dos quais não podemos nos furtar. Referimo-nos aqui à morte na sua iminência e como a possibilidade mais certa da existência ou seja, à mortalidade como condição do ser-aí - e não à morte como episódio "futuro" que encerrará a vida. Não se trata, portanto, da morte prevista, administrada, representada, mas, ao contrário, da morte como possibilidade certa [a possibilidade certa da impossibilidade e a possibilidade irremissível e intransferível], a possibilidade que se instaura no nascimento e que se vive, enquanto possibilidade, na angústia. O nascimento é, desta maneira, a instauração da mortalidade.

Acompanhando Heidegger cabe, porém, destacar duas modalidades da vivência de angústia: uma é a da angústia como agonia inominável (da qual se foge na direção dos entes); a outra é a da angústia como trânsito para a aceitação do tempo, do vir a ser dos entes, da morte, da finitude. A esta angústia pode caber, paradoxalmente, a noção de serenidade característica da decisão antecipadora em que se antecipa a morte no sentido preciso de que se aceita a mortalidade ["a angústia não inibe nem conturba"]. A serenidade - este permanecer no aberto deixando-ser, deixando-passar - pode ser compreendida 
como perda da onipotência (aceitação dos limites, da finitude). A serenidade é a disponibilidade para acolher o que nos vem ao encontro, ou seja, é a espera equânime do inesperado sem medo e sem ansiedade.

A temporalidade da/na angústia merece umas poucas palavras retrospectivas. Trata-se, fundamentalmente, da interrupção do "tempo funcional", o tempo do relógio, o tempo progressivo e unidirecional dos afazeres. Trata-se do retorno à temporalidade original: retorno aos fatos (aos limites) na direção do porvir.

$\mathrm{Na}$ interpretação heideggeriana da angústia e da finitude abre-se passo para, em um retorno à problemática psicanalítica, uma reconsideração nãopsicologizante do desamparo primordial e arquetípico e do seu "tempo", em que nascimento e morte serão tomados como fatos existenciais. Poderíamos dizer que nem a morte está no "futuro", nem o nascimento no "passado": eles estão sempre "agora", como o já-dado e como o porvir, instabilizando a existência, introduzindo em cada "agora" um dilaceramento interno, abrindo nele uma fenda.

É diante desta falha no ser, desta falta de ser ou falta em ser, que constitui o ser-aí, que a angústia heideggeriana assinala o não-funcional, o não-ajustado, o não-adaptado, como a fonte "arquetípica" de todos os perigos e de todos os medos e ainda das expectativas de perigo e das antecipações protetoras. "Arquétipo", contudo, que não pertence como origem a nenhum lugar ou momento do "passado" ontogenético (como seria o nascimento) ou filogenético, mas está a cada momento ativo como o irremediável já-dado e como o porvir iminente. Os medos e ansiedades, ainda que se originem desta condição e atualizem as possibilidades por ela instaurada, não a repetem senão modificando$a$ na direção de formas mais toleráveis de sofrimento e, fundamentalmente, desviando-se dela, deixando-a para trás e adiando seu (re)encontro. Medos e ansiedades são afetos dotados de sentido e de função. Mas eles se enraízam nesta disposição afetiva que ultrapassa o campo funcional, o campo do sentido, o plano do representável; emergem desta agonia inominável de que nos falou Winnicott, mas para evitá-la, para encobri-la.

\section{Angústia e alteridade (Freud e Lévinas - 1961, 1974)}

Nas considerações sobre Lévinas seremos ainda mais breves e esquemáticos.

Como vimos anteriormente, em Freud o desamparo primordial "angustiante" instalaria a abertura para a "ajuda alheia", que é ao mesmo tempo a instalação da/na significação, como traria para próximo o primeiro objeto hostil. ("Projeto...", p. 32, nota 94).

Em Lévinas, sugere-se aão expostos".

Mas Lévinas nos sinaliza também para as fraturas do eu-mesmo e para as exigências irrecusáveis do outro por acolhimento (na sua mortalidade, na sua 


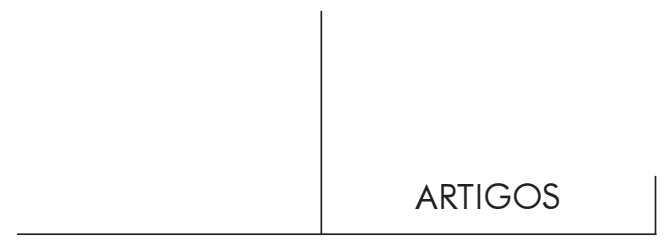

miséria, na sua vulnerabilidade, nas suas necessidades), impondo o desalojamento do próprio.

Assinale-se, assim, a "simultaneidade diacrônica" destes dois movimentos: da passividade e do desamparo primordiais irrompem tanto o grito de "socorro" endereçado ao outro acolhedor e provedor de sustentação e abrigo, como o grito de terror pela irrupção intrusiva do outro, pois o outro acolhedor é, "ao mesmo tempo", a maior fonte de risco de quebra e aniquilamento do próprio dadas as suas eventuais ausências, invasões, retaliações, rupturas de continuidade etc. Esta é a face persecutória da alteridade, o que produz, nos termos de Lévinas, uma verdadeira "alergia à alteridade". Os "seio bom" e "seio mau" em M. Klein fazem justiça a esta dupla face do outro, já vislumbrada por Freud em 1895. De acordo com esta ambivalência na relação com a alteridade, torna-se necessário pensar a constituição/separação "eu-não-eu" como pressupondo o outro como abrigo $e$ como ameaça, como casa $e$ como violência e efração, como refém $e$ como violador. Ou seja, torna-se necessário pensar tanto o holding como a sedução e o traumatismo como processos que intervêm na constituição da subjetividade (cf. Teoria da sedução generalizada de J. Laplanche), do que se origina o inconsciente como alteridade do/no próprio.

O momento da passividade mais passiva - o do encontro da alteridade - é o tempo irrecuperável da instituição/destituição do eu-mesmo: tempo irrecuperável (imemorial) porque tempo pré-histórico, tempo fora do tempo, tempo atemporal, tempo da angústia mais radical e originária, anterior a qualquer experiência, anterior a qualquer vivência, angústia, todavia, indispensável na instauração da subjetividade do homem e que desde então nela reside como sua condição de possibilidade e de impossibilidade.

\section{Retornando à psicanálise: repensar a angústia como pathos fundamental}

Trata-se, assim, para o psicanalista, tanto de enraizar-se no como de desembaraçar-se do paradigma funcionalista. $\mathrm{O}$ esquema funcionalista é necessário para se poder pensar a ansiedade e os medos como fenômenos funcionais e biologicamente significativos. Mas também é necessário poder pensar suas "origens" na angústia arquetípica e atemporal. Esta, por seu turno, deve ser pensada como "algo" que não é funcional nem, a rigor, desfuncional, nem é um fenômeno adaptativo nem, a rigor, desadaptativo, o que ainda seria conservar-se dentro da matriz funcionalista, mas como "algo" que diz respeito à condição humana e ao modo especial de vir a ser que nos caracteriza. 


\section{Referências}

Figueiredo, L.C. Matrizes do pensamento psicológico. Petrópolis, Vozes, 1991.

Freud, S. (1895). Projeto para uma psicologia. Tradução e notas de Osmyr Gabbi Jr.. Rio de Janeiro, Imago, 1995.

(1899). "Sobre los recuerdos encubridores", in Obras completas, vol. III.

Buenos Aires, Amorrortu, 1993, Trad. José Etcheverry.

(1920). "Más allá del princípio de placer", in Obras completas, vol. XVIII. Op. cit.

(1926). "Inhibicíón, síntoma y angustia", in Obras completas, vol. XX. Op. cit.

Lagrange, J. "Problématique du temps: phénomenologie et psychanalyse". Psychanalyse à l'Université, 1988, 13, 575-607.

Laplanche, J. Teoria da sedução generalizada. Porto Alegre, Artes Médicas, 1988.

Le Guen, C. A dialética freudiana I. Prática do método psicanalítico. São Paulo, Escuta, 1991.

LÉvinas, E. Totalité et infini. Essai sur l'exteriorité. La Havre, Nijhof, 1961.

Lingis, A. "Préface a l'édition americaine de Autrement qu'être". Cahier de l'Herne E. Lévinas, 1991, p. 137.

Heidegger, M. (1927). Ser e tempo, vols. I e II. (Trad. Márcia de Sá Cavalcanti). Petrópolis, Vozes, 1988, 1989,

Oliveira, R.M. "Angústia - emergência e soluções na clínica psicanalítica”. Brasília, UnB, Dissertação de Mestrado.

SCHNEIDER, M. "A proximidade em Lévinas e o Nebenmensch freudiano". (Trad. Martha Gambini). Cadernos de Subjetividade, 1997, 5, 7-90.

WinnicotT, D.W. "O medo do colapso", in Koноn, G. (org.) A escola britânica de psicanálise. (Trad. José Oc. de Aguiar Abreu). Porto Alegre, Artes Médicas, 1994, pp. 127-134.

"Recordações do nascimento, trauma do nascimento e ansiedade", in KHAN, M.M.R. (org.). Textos selecionados da pediatria à psicanálise. (Trad. de Jane Russo). Rio de Janeiro, Francisco Alves, 1978, pp. 313-339.

\section{Resumos}

El presente trabajo tiene como propósito sugerir que, no obstante las teorizaciones freudianas relativas a la angustia traigan las marcas de la matriz Funcionalista provinientes de la profunda inserción del autor en el campo de la biología evolucionista del siglo XIX, aquí, como en otras partes, la investigación psicoanalítica lleva Freud a romper com algunos de los presupuestos del funcionalismo. Basicamente los énfasis en la adaptación, en el auto-equilíbrio y en la temporalidad concebida en términos de evolución y desarollo debe ceder terreno frente a uma consideración mayor de la angustia en la experiencia humana. Es a partir de ahí que una interlocución com los filósofos Heidegger y Lévinas puede ser buscada como forma de facilitar la emergencia en el proprio cuerpo teórico y clínico 


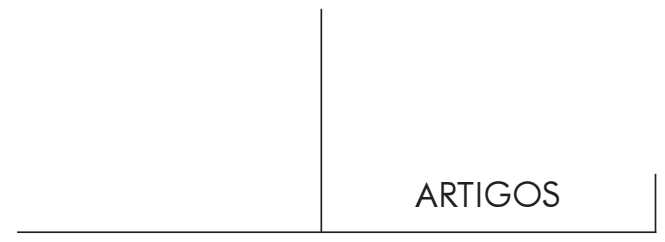

del psicoanálisis de algunas perspectivas ya vislumbradas por Freud y que no podrían ser plenamente acogidas en cuanto el pensamiento psicoanalítico permaneciese bajo el domínio del funcionalismo.

Le présent travail a pour but de suggérer que les théories freudiennes relatives à l'angoisse portent le sceau du paradigme fonctionnaliste à cause de la profonde insertion de Freud dans le champs de la biologie évolutionniste du XIXe siècle. Cependant, ici comme d'ailleurs, la recherche psychanalytique pousse Freud à rompre avec quelques principes du fonctionnalisme. Grosso modo, la mise en valeur de l'adaptation, de la tendance à l'auto-équilibration, tout comme l'accent sur la temporalité conçue en termes d'évolution et de développement doivent céder du terrain face à une considération plus attentive de l'angoisse dans l'expérience humaine. C'est à partir de là qu'on cherche, avec des philosophes comme Heidegger et Lévinas, un dialogue propice à faciliter l'emergence de quelques perspectives (dans le corps même de la théorie et de la clinique psychanalytique) déjà entrevues par Freud; ces perspectives ne pourraient pas s'épanouir si la pensée psychanalytique restait toujours sous la domination du fonctionalisme.

This paper suggests that freudian theories regarding anxiety carry the imprint of the functionalism paradigm due to Freud's deep insertion into the field of evolutionary biology at the end of XIX century. Neverthless, here as well as in other aspects, the psychoanalytic research has lead Freud to break up with some of the premises of the functionalism paradigm. Basically the importance of adaptation, of the tendency to auto-equilibrium, of temporality conceived as evolution and development should be undermined when a more careful consideration of anxiety in human experience takes place. It is at this very point that the contribution of philosophers like Heidegger and Lévinas can be valuable so that some perspectives already perceived by Freud may show in psychoanalitic practice and theory, perspectives which would not become visible while the functionalism paradigm would predominate in psychoanalytic thinking. 